\title{
USE-TECHNICAL SKILLS MAHASISWA PIAUD UNISMA DALAM LITERASI MEDIA DIGITAL
}

\author{
Yorita Febry Lismanda ${ }^{1}$, Ika Anggraheni ${ }^{2}$ \\ Program Studi Pendidikan Islam Anak Usia Dini Fakultas Agama Islam \\ Universitas Islam Malang
}

\begin{abstract}
The purpose of this research was to find out how personal media literacy personal competencies of students of PIAUD Unisma. In the form of how much to use -technical skills of students of PIAUD Unisma and the level of digital media literacy based on the component of usage skills. Research methods using qualitative research survey methods, data collection techniques using questionnaires and documentation. The results of the assessment using tabulation data technical skills from the questionnaire responses of respondents, showed the following results: (1) Basic, respondents who fall into this category as many as 5 people or 6.02 percent with a score between 1-5, (2) Medium, respondents who entered this category as many as 12 people or 14.46 percent score between 6-9, (3) Advanced, respondents who fall into this category as many as 66 people or 79.52 percent with a score between 10-14. From these results, the ability to use the technical skills of PIAUD Unisma students for the class of 2019/2020 is classified as very high or appropriate to the advanced category.
\end{abstract}

Keywords: personal competence, use-technical skills, digital media

\begin{abstract}
ABSTRAK
Tujuan penelitian ini untuk mengetahui sejauh mana personal competence literasi media digital mahasiswa PIAUD Unisma. Berupa sejauh mana use-technical skills mahasiswa PIAUD Unisma dan tingkat literasi media digital berdasarkan komponen use-technical skills. Metode penelitan menggunakan penelitan kualitatif metode survey, teknik pengumpulan data menggunakan kuisoner dan dokumentasi. Hasil scoring use-technical skills tabulasi data dari angket respon dari responden, menunjukkan hasil sebagai berikut: (1) Basic, responden yang masuk pada kategori ini sebanyak 5 orang atau 6,02 persen dengan skor antara 1-5, (2) Medium, responden yang masuk pada kategori ini sebanyak 12 orang atau 14,46 persen skor antara 6-9, (3) Advanced responden yang masuk pada kategori ini sebanyak 66 orang atau 79,52 persen dengan skor antara 10-14. Dari Hasil tersebut kemampuan use-technical skills mahasiswa PIAUD Unisma angkatan 2019/2020 tergolong sangat tinggi atau berada pada kategori advanced.
\end{abstract}

Kata Kunci: personal competence, use-technical skills, media digital

\footnotetext{
Korespondensi :

${ }^{1)}$ Yorita Febry Lismanda, Prodi Pendidikan Islam Anak Usia Dini Fakultas Agama Islam Universitas Islam Malang, Email:-

${ }^{2)}$ Ika Anggraheni, Prodi Pendidikan Islam Anak Usia Dini Fakultas Agama Islam Universitas Islam Malang
} 


\section{PENDAHULUAN}

Peradaban manusia di segala penjuru dunia tidak terlepas dari revolusi industri yang membawa perubahan signifikan. Perubahan yang dimulai dari revolusi industri 1.0 yang ditandai dengan adanya mekanisasi serta energi uap dan air. Revolusi industri 2.0 merubah peradadaban dengan munculnya energi listrik dan motor. Selanjutnya berkembang revolusi industri 3.0 dengan tumbuhnya industri elektronika, teknologi informasi. Tidak berhenti disini, sekarang berkembang era industri 4.0 yang ditandai dengan internet oflfor things (IoT) dimana teknologi informasi otomatisasi yang terjadi diseluruh bidang kehidupan dengan teknologi dan pendekatan baru berbasis AI yang merupakan penggabungan antara kehidupan nyata dan digital secara fundamental (Tjandrawinata, 2016).

Industri 4.0 pada dasarnya merupakan penyempurnaan dari industri 3.0 dimana menggabungkan teknologi otomatisasi dengan teknologi cyber atau media digital. Kecepatan perubahan yang terjadi pada masa industri 4.0 adalah keniscayaan yang tidak dapat dihindari. Salah satunya yaitu terjadinya kemampuan mesin, perangkat, sensor, dan manusia untuk terhubung dan saling berkomunikasi satu sama lain melalui internet untuk segalanya (IoT). Sehingga penggunaan media digital (internet) menjadi tren yang telah mengubah life style manusia. Keberadaan internet sebagai pendukung perangkat elektronik mendorong perubahan fenomena kehidupan secara signifikan yang berdampak dan mengubah cara pandang dan kehidupan masyarakat beberapa tahun ini (Yu, 2011)

Berbagai tantangan yang berasal dari side effect dan peluang yang berasal dari benefits adanya IoT pun bermunculan. Salah satu tantangan yang muncul yaitu pengurangan lapangan pekerjaan dikarenakan Sumber Daya Manusia (SDM) yang tergantikan oleh robot. Sedangkan peluang yang muncul salah satunya adalah percepatan investasi berbasis teknologi.

Untuk memanimalisir side effect tersebut, sumber daya manusia yang dalam hal ini generasi muda perlu bersusah payah untuk belajar dan mengasah keterampilan yang sesuai dengan kebutuhan era industri 4.0. Termasuk mahasiswa yang notabene merupakan generasi muda penerus bangsa yang menempuh pendidikan di perguruan tinggi. Mahasiswa harus memiliki daya saing yang kuat di tengah derasnya 
persaingan era industri 4.0 sehingga mahasiswa menjadi pelaku aktif yang mendapat manfaat atas perubahan besar itu.

Literasi yang terbentuk di era digital sudah barang tentu berbeda dengan literasi yang terbentuk di era industri sebelumnya. Literasi digital menunjuk pada praktik-praktik komunikasi, menjalin relasi, berpikir, dan aktivitas lain yang berkaitan dengan media digital. Mengembangkan pengertian literasi digital ialah bagian dari upaya memahami bagaimana media memberikan dampak terhadap berbagai jenis praktik literasi yang muncul, termasuk bagaimana praktik membaca dan menulis yang berkembang karena pengaruh penggunaan teknologi digital. Dengan kata lain, literasi media digital di sini tidak hanya berkaitan dengan keterampilan dan strategi dalam menentukan kualitas, keandalan, validitas, tujuan, dan maksud dari informasi yang diakses di dunia digital (critical understanding), serta kemampuan beradaptasi dengan aktivitas-aktivitas yang termediasi teknologi digital termasuk praktik-praktik sosial termediasi (communicative abilities), melainkan juga kemampuan teknis mengoperasionalkan perangkat/ komputer sebagai peralatan media digital (use-technical skills).
Berkaitan dengan hal tersebut, maka peneliti berusaha melakukan penelitian sejauh mana use-technical skills mahasiswa PIAUD Unisma dalam literasi media digital. Fenomena tingginya penggunaan media digital harus diimbangi pula dengan pemahaman yang baik akan fungsi media tersebut. Dengan demikian maka pengetahuan mengenai usetechnical skills media digital menjadi kemampuan yang harus dimiliki mahasiswa PIAUD Unisma. Hal ini diperlukan agar mahasiswa memiliki kesiapan mental dalam menghadapi berbagai tantangan di era revolusi industri 4.0, tidak menjadi internet addiction, dan diharapkan memiliki keterampilan lanjutan dalam penggunaan internet.

Oleh karena itulah penelitian ini dilakukan dengan tujuan mengetahui sejauh mana personal competence literasi media digital mahasiswa PIAUD Unisma. Berupa sejauh mana use-technical skills mahasiswa PIAUD Unisma dan tingkat literasi media digital berdasaarkan komponen use-technical skills. Hasil penelitian ini juga diharapkan menjadi landasan dalam menentukan berbagai kebijakan institusi untuk meningkatkan efektifitas pembelajaran di kampus. 


\section{METODE PENELITIAN}

Penelitian ini menggunakan penelitian kualitatif dengan membuat deskripsi mengenai situasi-situasi atau kejadian-kejadian. Lokasi penelitian di Kampus Universitas Islam Malang, Jalan MT. Haryono No. 193, DinoyoLowokwaru, Malang. Dengan subjek penelitian adalah mahasiswa PIAUD Unisma tahun ajaran 2019/2020 berjumlah 83 orang.

Teknik pengumpulan data menggunakan kuisoner dan dokumentasi. Instrumen kuisoner berisi komponenkomponen use-technical skills mahasiswa PIAUD Unisma dalam literasi media digital menggunakan google form, serta dokumentasi pelaksanaan penelitian yang disesuaikan dengan komponen-komponen use-technical skills.

Analisis data dilakukan secara kualititatif dengan reduksi data, penafsiran/pemaknaan data, dan penyimpulan hasil analisis. Data yang diperoleh melalui kuisioner dan dokumentasi kemudian ditulis ulang, dipaparkan apa adanya, kemudian dipilahpilah sesuai fokus penelitian. Setelah melalui proses reduksi dalam kerangka akan diperoleh data yang shahih dengan member check, triangulasi, dan pelacakan mendalam, yang kemudian ditafsirkan/dimaknai. Selanjutnya data yang telah dimaknai kemudian ditarik hasil analisis.

\section{HASIL DAN PEMBAHASAN}

\section{A. Kemampuan Use-Technical Skills Mahasiswa PIAUD Unisma}

Use-technical skills merupakan bagian dari kemampuan personal competences dalam menggunakan media. Use-technical skills adalah kemampuan seseorang dalam mengoperasikan dan menggunakan media tertentu secara efektif. Kemampuan akses penggunaan media digital bagi seseorang bergantung pada jenis media digital, kebutuhan, dan fungsi spesifik dari media digital. 


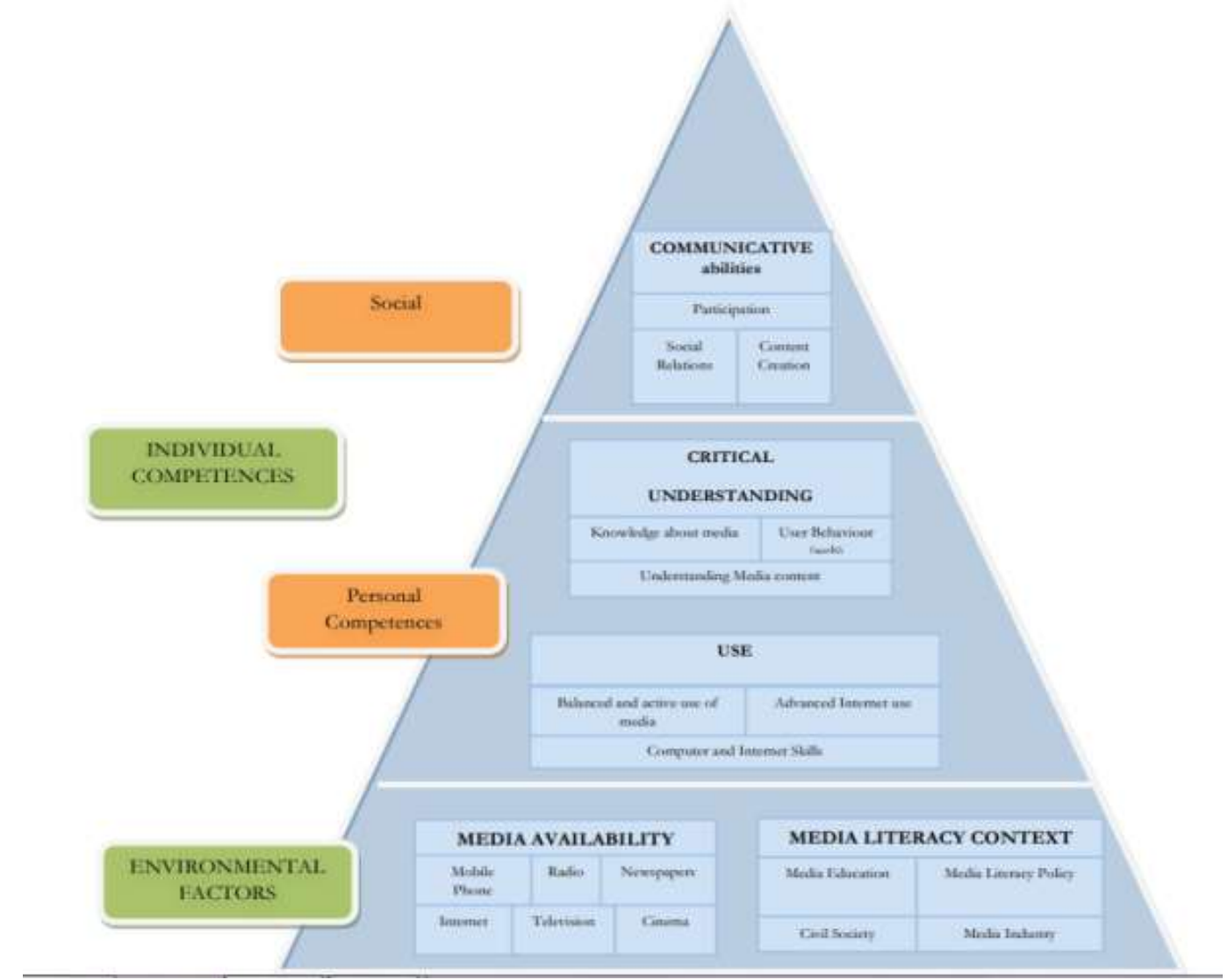

Gambar 1. Framework Kriteria Penilaian Literasi (Media Digital (EAVI, 2009))

Berdasarkan hasil survey yang dilakukan kepada 83 mahasiswa PIAUD angkatan 2019/2020 dapat dipaparkan hasil use-technical skills melalul tiga dimensi/ bagian pertanyaan yaitu computer and internet skill (keterampilan gabungan antara perangkat dan internet), balanced and active use media (penggunaan internet yang aktif dan seimbang) dan advance internet skill (penggunaan internet lanjutan). Dari ketiga bagian pertanyaan tersebut dapat dipaparkan data sebagai berikut:

Petama, computer and internet skill (keterampilan gabungan antara perangkat dan internet), kemampuan ini terdiri dari dua bagian yaitu kemampuan menggunakan komputer dan kemampuan penggunaan internet. Pada kemampuan menggunakan komputer dari 83 responden secara garis besar hampir semua responden mampu menggunakan komputer, namun pada kemampuan membuat akun pengguna pada komputer/laptop terdapat $20,5 \%$ atau hampir $1 / 4$ responden tidak bisa membuat. Selain itu juga terdapat $37,3 \%$ responden tidak bisa ketika ditanyakan kemampuan menginstal aplikasi/program di komputer /laptop, padahal kemampuan menginstal 
sebuah aplikasi/program pada komputer atau laptop merupakan kemampuan dasar seseorang dalam menggunakan komputer apalagi dalam kegiatan pembelajaran seringkali ketika perlu adanya bantuan

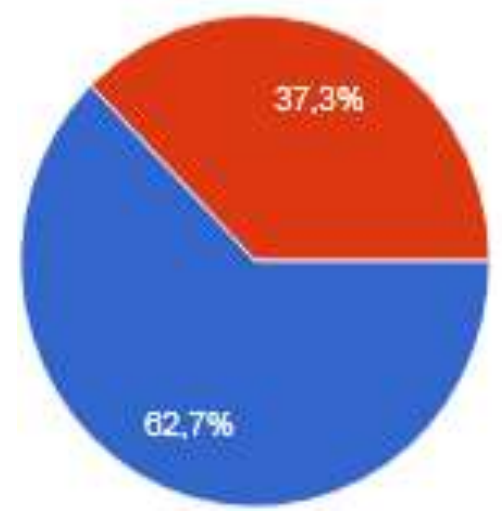

suatu aplikasi/program termasuk aplikasi yang berkaitan dengan pembelajaran dalam rangka mempermudah pemahaman mahasiswa memahami materi.

Gambar 2. Kemampuan Menginstal Aplikasi/Program di Komputer/Laptop

Pada kemampuan menggunakan internet $90,4 \%$ responden mampu menggunakan internet atau menghubungkan device pada jaringan internet. Mayoritas responden menggunakan handphone /tablet dalam mengakses internet atau sebanyak 92,8\% responden dengan browser yang banyak digunakan untuk browsing adalah aplikasi chrome sebanyak $77,1 \%$ baik

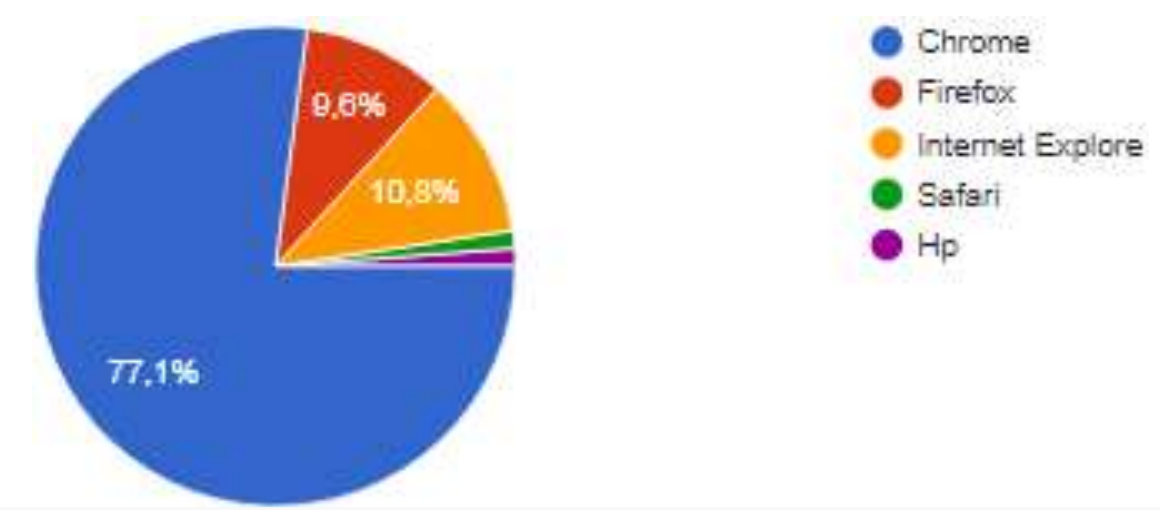

Gambar 3. Browser yang Sering Digunakan Responden menggunakan komputer atau handphone, meskipun kebanyakan responden menggunakan handphone dalam menggunakan akses internet hanya terdapat $1,2 \%$ yang menggunakan browser bawaan handphone ketika browsing, hal ini mengisyaratkan bahwa aplikasi google chrome merupakan aplikasi paling popular digunakan oleh responden. 
Kedua, balanced and active use media (penggunaan internet yang aktif dan seimbang). Kemampuan ini terdiri dari tiga bagian yaitu penggunaan internet, kepemilikan akun sosial media dan situs yang sering dikunjungi. Pada penggunaa internet untuk kuota yang digunakan responden dalam rentang waktu 1 bulan sekitar $47 \%<10 \mathrm{~GB}, 18,1 \%>30 \mathrm{~GB}, 18 \%$ 10-15GB dan sisanya menggunakan kuota

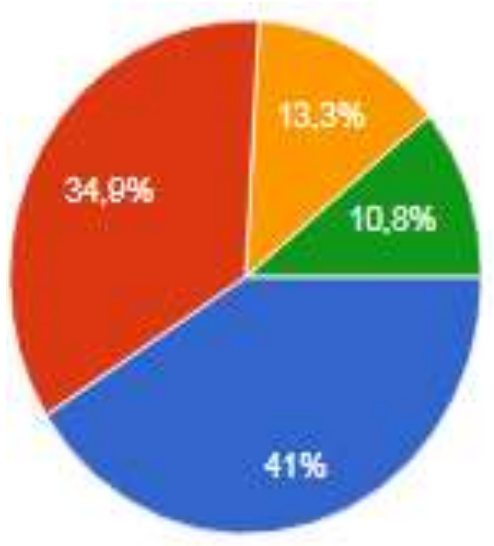

Gambar 4. Rata-rata Online Responden dalam 1 hari di rentang 15-30GB dengan operator yang banyak digunakan oleh responden adalah telkomsel $31,3 \%$ dan indosat $24,1 \%$ sementara itu lama rata-rata online menggukana internet dalam 1 hari sebanyak 41\% 1-5 jam, 34,9\% 5-10 jam, 13,3\% 10-15 jam dan 10,8 \% lebih dari 15 jam. Data-data tersebut menjelaskan bahwa kebutuhan responden akan jaringan internet sangat besar.
Pada bagian kedua tentang kepemilikan akun social media mayoritas responden memiliki akun social media, dengan akun yang paling banyak dimiliki responden dengan akun yang paling sering digunakan adalah instagram 32,5\% dan facebook $30,1 \%$ dan sisanya berupa adalah whatsapp, twitter dan youtube. Situs yang sering dikunjungi oleh responden adalah social media 54.2\%, situs video $24,1 \%$, berita $16,9 \%$ dan sisanya adalah e-commerce, blog dan komunitas online. 


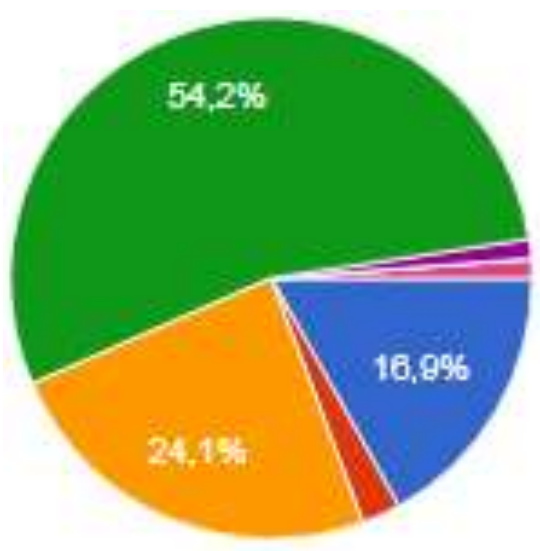

Berita

- E-commerce (Tokopedia, Shoope, Buksiapak, Lazads, dil)

Situs Video (Youtube, Vimeo, dll)

Socisl Medis (Fscebook, Instagram, Tvitter dil)

Blogiwebsite pribadi

- Game online

Komunitas online

Gambar 5. Situs yang sering dikunjungi

Ketiga, advanced internet skill internet sedangkan mengupload file (penggunaan internet lanjutan), Terdapat $81,9 \%$ responden bisa mengupload dan dua bagian pada kemampuan ini yaitu $18,1 \%$ tidak bisa mengupload file. File kemampuan download dan upload serta yang sering di download responden adalah kemampuan berberlanja/ membeli secara musik sebanyak $32,5 \%$ dan jurnal online. Data kemampuan download dan menduduki peringkat kedua sebanyak upload file responden sebanyak $99,8 \% \quad 24,1 \%$. responden bisa mendownload file di
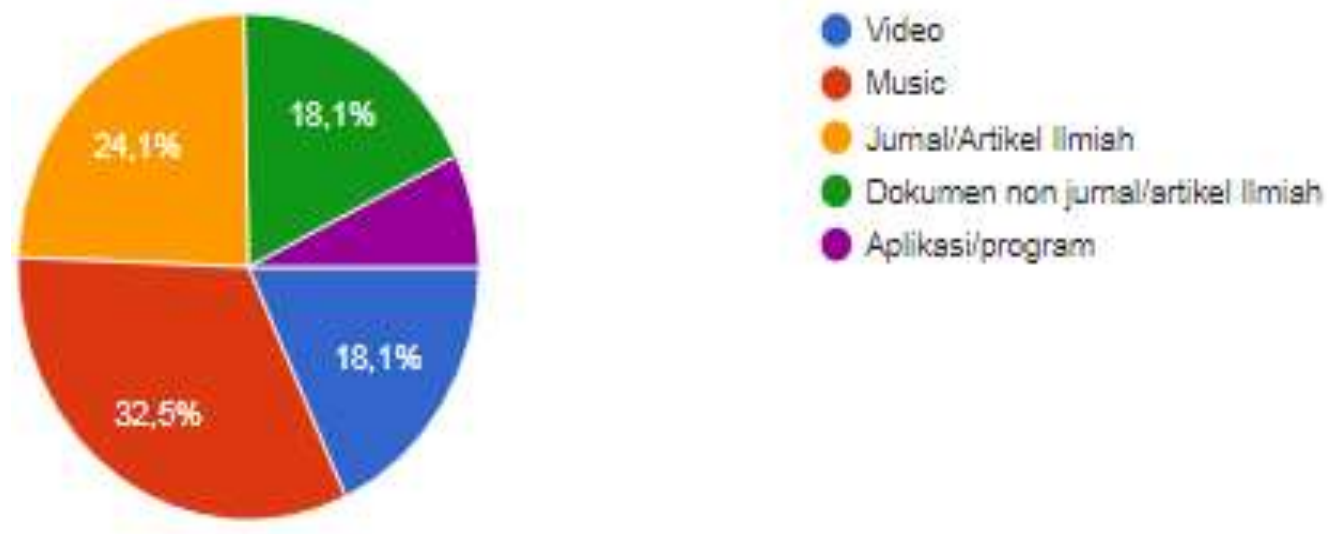

Gambar 6. File yang sering didownload

Dari data tersebut dapat dipahami bahwa tidak sampai $1 / 4$ dari responden mendownload artikel ilmiah yang artinya budaya membaca responden terhadap kajian-kajian ilmiah masih kurang. 
B. Tingkat Kemampuan Use- sebanyak 66 orang atau 79,52\% dengan Technical Skills Mahasiswa PIAUD skor antara 10-14. Dari Hasil tersebut Unisma

kemampuan use-technical skills

Setelah mengetahui bobot mahasiswa PIAUD Unisma angkatan kemampuan individu pada setiap 2019/2020 tergolong sangat tinggi atau komponen, selanjutnya dianalisis ketiga berada pada kategori Advanced.

komponen penilaian seluruh individu.

Hasil perhitungan tersebut selanjutnya akan menentukan use-technical skills mahasiswa PIAUD Unisma dalam literasi media digital. Dalam hal ini, tingkat kemampuan literasi media dibedakan menjadi tiga kategori, yaitu basic, medium, dan advanced.

Hasil scoring use-technical skills tabulasi data dari angket respon dari responden, menunjukkan hasil sebagai berikut: (1) Basic, responden yang masuk pada kategori ini sebanyak 5 orang atau $6,02 \%$ dengan skor antara 1-5, (2) Medium, responden yang masuk pada kategori ini sebanyak 12 orang atau 14,46\% skor antara 6-9, (3) Advanced

\section{SIMPULAN}

Berdasarkan paparan hasil diatas dapat disimpulkan bahwa mahasiswa PIAUD memiliki kemampuan usetechnical skills yang sangat baik dengan tingkat kemampuan $79,52 \%$ atau lebih dari $3 / 4$ responden yang merupakan mahasiswa PIAUD memiliki tingkat kemampuan use-technical skills pada kategori advanced.

Harapan dari hasil penelitian tersebut dapat dijadikan acuan oleh berbagai pihak terkait dalam melakukan aktivitas pembelajaran yang efektif dan efisien di kampus khususnya dalam upaya peningkatan literasi media digital.

responden yang masuk pada kategori ini

\section{DAFTAR PUSTAKA}

EAVI. 2009. Study on assesment criteria for media literacy levels. Brussels.

Tjandrawina, R.R. (2016). Industri 4.0: Revolusi industri abad ini dan pengaruhnya pada bidang kesehatan dan bioteknologi. Jurnal Medicinus, Vol 29, Nomor 1, Edisi April.

Yu, C. S., (2011), Construction and validation of an e-lifestyle instrument, Internet Research 
